\title{
COVID-19 Treatment-Review of All Published Literatures till Date
}

\section{Rajib Dutta*}

MD Neurology, India

*Corresponding Author: Rajib Dutta, MD Neurology, India.

Email:rajibdutta808@gmail.com

ORCID: orcid.org/0000-0002-6129-1038
Received: March 25, 2020

Published: April 01, 2020

(C) All rights are reserved by Rajib Dutta.

\section{Abstract}

The outbreak of SARS-COV-2 (severe acute respiratory syndrome coronavirus 2), that began in December 2019, is still spreading worldwide and presents a significant and urgent threat to global health and economy. Patients with COVID-19 are at risk of acute respiratory distress syndrome (ARDS), respiratory failure and death. Patients aged > 60 years with comorbidities, children and health care workers are highly vulnerable to this virus. The tissue receptor for COVID-19 is Angiotensin-converting enzyme 2 (ACE2) and higher levels of ACE2 can protect against ARDS. Scientists all over the world are actively working to explore drugs or antivirals specific to the virus. Several agents has been reported to be effective, however trials are on currently. Here in this review all therapeutic agents against COVID-19 reported in recent times after the outbreak are being discussed.

Keywords: SARS-COV-2; COVID-19; Treatment

\section{Abbreviations}

SARS-COV-2: Severe Acute Respiratory Syndrome Coronavirus 2; COVID-19: Corona Virus Disease, 2019; MERS: Middle East Respiratory Syndrome; SARS: Severe Acute Respiratory Syndrome; LPV: Lopinavir; RTV: Ritonavir; FPV: Favipiravir; ACEI: Angiotensin Converting Enzyme Inhibitors; AT1R: Angiotensin II Type I Receptor; TMPRSS2: Transmembrane Serine Protease 2

\section{Introduction}

Coronavirus disease 2019, known as COVID-19 is spreading rapidly across the globe. It is caused by SARS-COV2 and is considered to be the causative agent of a potentially fatal disease of great public health concern. Till now researchers have reported about pneumonia as one of the most important complication after contracting the virus leading to respiratory failure, hemodynamic comprise and death. However, some literatures has also reported about involvement of heart, liver, gastrointestinal tract and even central nervous system. It is considered to have started from a wet market in wuhan, china and then slowly human to human transmission was reported worldwide leading to a pandemic and affecting roughly 392, 230 persons, 17,147 deaths, recovered 103, 389 till $24^{\text {th }}$ march 2020 , when the article was drafted [1].

Extensive measures to reduce person-to-person transmission of COVID-19 have been implemented worldwide to control the current outbreak but efficacy is not known yet due to unexpected rise of cases in clusters in various geographic location. It was known that the spread of virus was very significant in countries with low temperature, however now lots of cases are also being reported from countries in south east Asia, middle east where temperature is expected to be between 30 - 40 degree Celsius [1]. Children, health care providers and elderly people are the most susceptible population needing special attention to protect or reduce transmission. Though containment measures like effective hand hygiene i.e. hand washing is the norm currently however, need for vaccine and other therapeutic agents effective in killing or containing the multiplication of virus or inducing immunity has become need of the hour. Researchers are working worldwide on vaccine and testing various pharmaceutical agents which can be major breakthrough in context of COVID-19 treatment in recent future. Here in this article, all published literatures regarding treatment of this deadly virus will be reviewed.

\section{Drugs under consideration for COVID-19}

Recent reports has suggested about Chloroquine/Chloroquine phosphate or Hydroxychloroquine (HCQ), usually used for treating malaria having an apparent efficacy and acceptable safety against COVID-19 associated pneumonia in multicenter clinical trials conducted in China [2-5,33], in line with literature published by Touret., et al [21]. A systematic review on the efficacy and safety of chloroquine for the treatment of COVID-19 published by Cortegiani and colleagues suggested inspite of having pre-clinical evidence of effectiveness and safety evidence from long-time clinical use for other indications, more safety data and data from high-quality clinical trials are urgently needed in COVID-19 patients in different set up [29]. Devaux., et al. also reported the role of chloroquine/ hydroxychloroquine interfering with the SARS-CoV-2 replication cycle [30]. Hydroxychloroquine was found to be more potent than chloroquine to inhibit SARS-CoV-2 in vitro [38]. HCQ is likely to attenuate the severe progression of COVID-19, inhibiting the 
cytokine storm by suppressing $\mathrm{T}$ cell activation, can be used in pregnant women and have less side effects than chloroquine [39]. Dose of chloroquine phosphate is $500 \mathrm{mg}$ ( $300 \mathrm{mg}$ for chloroquine) bd p. $0 .<=10$ days [52]. Hydroxychloroquine on the other hand has been used by U.S clinicians in different dosing pattern $400 \mathrm{mg}$ $\mathrm{BD}$ on day one, then daily for 5 days; $400 \mathrm{mg}$ BD on day one, then $200 \mathrm{mg}$ BD for 4 days; $600 \mathrm{mg}$ BD on day one, then $400 \mathrm{mg}$ daily on days 2 - 5 [53].

Remdesivir is a novel antiviral drug in the class of nucleotide analogs. It was developed by Gilead Sciences, as a treatment for Ebola virus disease and Marburg virus infections [6]. It has subsequently also been found to show antiviral activity against other single stranded RNA viruses such as respiratory syncytial virus, Hendra virus, and the coronaviruses (including MERS and SARS viruses) [7-9]. It is currently being studied for SARS-CoV-2 which could be promising drug candidate to treat coronavirus $[4,10,11]$. Remdesivir was used to treat an American patient in Snohomish County, Washington in 2020, who was infected with SARS-CoV-2 [12] and his condition improved dramatically and discharged within $24 \mathrm{hrs}$ after admission [13]. Gilead is currently providing the compound to China to conduct a pair of trials in infected individuals with and without severe symptoms [14-16]. On 17 March 2020, remdesivir was provisionally approved for use for COVID-19 patients in a serious condition in Czech Republic [17]. On 18 March 2020, the first Italian 79 year old COVID-19 patient was successfully treated with remdesivir in Genoa [18]. Dosing regimen is IV $200 \mathrm{mg}$ on day one, followed by a $100 \mathrm{mg}$ every day until day five or ten [54].

In late January 2020, exploratory research showed Favipiravir (FPV), seemed to have "fairly good inhibitory effects" on SARSCoV-2 at the cellular level [19] and had more potent antiviral action than that of lopinavir/ritonavir [25]. Dose of FPV, Day 1: $1600 \mathrm{mg}$ twice daily; Days 2-14: 600 mg twice daily [55].

Lim., et al. in their paper reported about a 54-year old male patient from Korea with COVID-19, an index patient first to cause tertiary transmission outside China, developed pneumonia on day 6 of admission and after receiving Lopinavir (LPV)/Ritonavir (RTV) (Kaletra, AbbVie), $\beta$-coronavirus viral loads significantly decreased and no or little coronavirus titers were observed [20]. Cao., et al. conducted a randomized, controlled, open-label trial involving hospitalized adult patients with confirmed SARS-CoV-2 involving lopinavir-ritonavir (400 $\mathrm{mg}$ and $100 \mathrm{mg}$, respectively) twice a day PO for 14 days and they concluded that in hospitalized adult patients with severe COVID-19, no benefit was observed with lopinavir-ritonavir treatment beyond standard care and the drug was stopped early in several patients because of serious gastrointestinal adverse events [26]. Liu., et al. in their research studied about Lopinavir-combined regimen in ten patients admitted with COVID-19 and reported viral load of SARS-CoV-2, radiography and eosinophil counts improved continuously in $3-14,6-8$ and 7 - 9 days, respectively post treatment. Increased eosinophil count may predict the outcome of COVID-19 progression [28]. Dong., et al. in their paper reported about the standard dose of LPV/RTV as $200 \mathrm{mg} / 50 \mathrm{mg} /$ capsule, 2 capsules each time, 2 times/day PO < = 10 days [52].

IFN- $\alpha 5$ million $U$ or equivalent dose each time, 2 times/day vapor inhalation $<=10$ days and Ribavirin $500 \mathrm{mg}$ each time, 2 to 3 times/day in combination with IFN- $\alpha$ or lopinavir/ritonavir IV < = 10 days, has also been implicated in treatment of COVID-19 [22,52] and Arbidol $200 \mathrm{mg}$ each time, 3 times/day PO was later added into the list based on the preliminary outcomes of clinical studies $[23,52]$. Deng., et al. performed a retroprospective cohort study on arbidol combined with LPV/r versus LPV/r alone in COVID- 19 for 5 - 21 days and found combination therapy better than monotherapy [30].

Baron., et al. reported about Teicoplanin, an antibiotic used to treat staphylococci infection, previously showed efficacy to inhibit the first stage of MERS-coronavirus viral cycle in human cells has the same inhibiting action against SARS-CoV-2 in vitro, thus placing teicoplanin as a potential treatment for patients with this COVID-19 but further works are needed to confirm its activity in vivo [27]. The concentration of teicoplanin required to inhibit 50\% of viruses (IC50) in vitro was $1.66 \mu \mathrm{M}$, which is much lower than the concentration reached in human blood $(8.78 \mu \mathrm{M}$ for a daily dose of $400 \mathrm{mg}$ ) [56].

Battle., et al. reported about the S1 domain of the spike protein of SARS-CoV attaching the virus to its cellular receptor ACE2 on the host cells. This connection between the SARS-CoV, SARS-CoV-2, ACE2 forms the rationale for soluble ACE2 as a potential therapy [42]. Sun., et al. reported ACEI and AT1R inhibitors working on RAS pathway could be used in patients with COVID-19 pneumonia under the condition of controlling blood pressure, which might reduce the pulmonary inflammatory response and mortality [32], also reported by David Gurwitz [47].

Systemic glucocorticosteroid is recommended as a short term use $(1 \sim 2 \mathrm{mg} / \mathrm{kg} / \mathrm{d})$ for $3 \sim 5$ days for new corona virus pneumonia(NCP) is drafted into the 5 th edition National Health Commission's Regimen yet RCTs are expected to confirm the effectiveness [34,46]. Zhu., et al. reported about a 52-year-old renal transplant patient with COVID-19 treated successfully with IV Methylprednisolone, Intravenous immunoglobulin, Interferon a after stopping all the immunosuppressive agents he was receiving 
post transplant namely, tacrolimus, mycophenolate mofetil, prednisone $[41,48]$. There is a role of convalescent plasma, and monoclonal antibodies also $[35,37,50]$.

Chen., et al. in their retroprospective analysis with nine patients, only two patients with diarrhea was treated with montmorillonite powder (3g, three times a day) or trigeminy viable organism powder $(1 \mathrm{~g}$, three times a day) to arrest diarrhea or regulate intestinal flora. Cases with severe infection was treated with combination therapy of interferon alfa-2b (10 million IU daily), lopinavir and ritonavir tablets (800/200 mg daily), methylprednisolone (40 mg daily), moxifloxacin hydrochloride (0.4g daily) and high-flow nasal oxygen therapy and additional intravenous immunoglobulin $(200$ $\mathrm{mg} / \mathrm{kg}$ daily) and thymalfasin (1.6 mg twice a week). Traditional Chinese medicine (Qingfei Paidu Decoction) were used for preventing and treating pulmonary fibrosis [36].

Chen YW., et al. used 3C-like protease (3CL pro) threedimensional molecular model and found out antivirals like Ledipasvir or Velpatasvir are good therapeutic options for consideration to combat the new coronavirus with minimal side effects, commonly fatigue and headache. Two drugs used for viral hepatitis namely Epclusa (velpatasvir/sofosbuvir) and Harvoni (ledipasvir/sofosbuvir) could be very effective owing to their dual inhibitory actions on two viral enzymes [40].

Fan., et al. reported Cepharanthine (CEP), Selamectin and Mefloquine hydrochloride exhibited complete inhibition of cytopathic effects in cell culture at $10 \mu \mathrm{mol} / \mathrm{L}$, which can be potential drugs for treating 2019-nCoV infection. They strongly suggested CEP is a wide-spectrum inhibitor of pan-betacoronavirus [43].

Hoffmann., et al. suggested that TMPRSS2 could be a potential therapeutic target for COVID-19 since entry into cells was reduced by Camostat mesylate, a TMPRSS2 inhibitor [45]. Xu., et al. has reported about the broad antiviral activity of Niclosamide a FDA approved antihelminthic drug and highlighted its potential clinical use in the treatment of COVID-19 [49]. Richardson., et al. reported Baricitinib, sold under the brand name Olumiant, is an orally available small molecule inhibitor of Janus kinases that is used to treat moderate-to-severe rheumatoid arthritis, as a potential treatment for COVID-19 [51].

A joint researcheal team of Shanghai Institute of Materia Medica and Shanghai Tech University reported 30 agents including potential traditional Chinese medicines with potential antiviral activity against SARS-CoV-2 on January 25, $2020[24,44]$.

\section{Discussion}

This recent outbreak of coronavirus disease 2019 (COVID-19) caused by the novel coronavirus named as severe acute respiratory syndrome coronavirus 2 (SARS-CoV-2) started in Wuhan, China, at the end of 2019. It is characterized by ARDS, respiratory failure followed by death if the bodies immune system is not able to fight against it. Children, health care workers, elderly people with comorbidities are prone to get this infection, however recent reports coming from USA and Italy also shows people in age group of 20 - 40 years are alsosusceptible to it.

As the pandemic spreads across the globe, researchers and scientists are busy around the world, actively exploring drugs and drug-drug combinations that would be effective in combating COVID-19. Unfortunately, there is no specific antiviral agent present at this moment to treat patients in any type of set up. The drugs which we have discussed earlier are approved for microbial agents other than COVID-19. However, studies around the world has shown that these drugs can be used to decrease the level of infection and thereby decrease the spread. Drugs mentioned in the manuscript are currently under trials and hopefully gets approved by drug licensing companies.

\section{Conclusion}

The efficacy and safety of these candidate drugs mentioned in this article in the treatment of COVID-19 need to be confirmed in randomized controlled trials before its used as a licensed drug against COVID-19. These drugs if found effective can minimize human to human spread and buy some time for researchers and scientists for successful development of a vaccine.

\section{Search Strategy}

PubMed literature screening was done with the following keywords "SARS-COV-2" AND "COVID-19" AND "treatment" with no time limit. All literatures falling in the scope of the review article was selected and used. Hand searching was used in Google Scholar to fetch relevant articles.

\section{Acknowledgement}

The author has no relevant affiliations or financial involvement with any organization or entity with a financial interest in or financial conflict with the subject matter or materials discussed in the manuscript. Thanks to my mentor Prof. Hui Fang Shang for constant support and Dr Swati for revising the drafted manuscript.

\section{Bibliography}

1. COVID-19 Coronavirus Pandemic.

2. Gao J., et al. "Breakthrough: Chloroquine phosphate has shown apparent efficacy in treatment of COVID-19 associated pneumonia in clinical studies". BioScience Trends 14.1 (2020): 7273.

3. Audio transcript of the news briefing held by the State Council of China on February 17, 2020. The National Health Commission of the People's Republic of China (2020). 
4. Wang M., et al. "Remdesivir and chloroquine effectively inhibit the recently emerged novel coronavirus (2019-nCoV) In vitro". Cell Research 30.3 (2020): 269-271.

5. Chinese Clinical Trial Registry.

6. Warren TK., et al. "Therapeutic efficacy of the small molecule GS-5734 against Ebola virus in rhesus monkeys". Nature 531.7594 (2016): 381-385.

7. Sheahan TP., et al. "Broad-spectrum antiviral GS-5734 inhibits both epidemic and zoonotic coronaviruses". Science Translational Medicine 9.396 (2017): eaal3653.

8. Agostini ML., et al. "Coronavirus Susceptibility to the Antiviral Remdesivir (GS-5734) Is Mediated by the Viral Polymerase and the Proofreading Exoribonuclease". mBio 9.2 (2018): e00221-E002218.

9. Lo MK., et al. "GS-5734 and its parent nucleoside analog inhibit Filo-, Pneumo-, and Paramyxoviruses". Scientific Reports 7 (2017): 43395.

10. Remdesivir could be promising drug candidate to treat coronavirus. Coronavirus daily update (2020).

11. Brunk D. "Remdesivir Under Study as Treatment for Novel Coronavirus". Medscape (2020).

12. Holshue ML., et al. "First Case of 2019 Novel Coronavirus in the United States". The New England Journal of Medicine 382.10 (2020): 929-936.

13. Harmon A. "Inside the Race to Contain America's First Coronavirus Case". The New York Times (2020).

14. Johnson CY. "Scientists Hope an Antiviral Drug Being Tested in China Could Help Patients". The Washington Post (2020).

15. Taylor NP. "Gilead mulls repositioning failed Ebola drug in China virus". Fierce Biotech (2020).

16. Joseph SS and Samuel M. "Gilead working with China to test Ebola drug as new coronavirus treatment". Thomson Reuters (2020).

17. https://www.mzcr.cz/Soubor.ashx?souborID=40603\&typ=a pplication/pdf\&nazev=0pat\%C5\%99en $\%$ C3\%AD\%20-\%20 LP\%20Remdesivir.pdf

18. Coronavirus: a Genova c'è primo guarito con Remdesivir (2020).

19. Zhao Y. "Three drugs fairly effective on novel coronavirus at cellular level". China News Service (2020).

20. Lim J., et al. "Case of the Index Patient Who Caused Tertiary Transmission of COVID-19 Infection in Korea: the Application of Lopinavir/Ritonavir for the Treatment of COVID-19 Infected Pneumonia Monitored by Quantitative RT-PCR". Journal of Korean Medical Science 35.6 (2020): e79.
21. Touret F and de Lamballerie X. "Of chloroquine and COVID-19”. Antiviral Research 177 (2020): 104762.

22. "Guidelines for the Prevention, Diagnosis, and Treatment of Novel Coronavirus-induced Pneumonia". The $5^{\text {th }}$ edition (2020).

23. "Guidelines for the Prevention, Diagnosis, and Treatment of Novel Coronavirus-induced Pneumonia". The $6^{\text {th }}$ edition (2020).

24. Shanghai Institute of Materia Medica website, Chinese Academy of Sciences. A joint research team of the Shanghai Institute of Materia Medica and Shanghai Tech University discover a group of old and traditional Chinese medicines that may be efficacious in treating the novel form of pneumonia (2020).

25. News (2020).

26. Cao B., et al. "A Trial of Lopinavir-Ritonavir in Adults Hospitalized with Severe Covid-19 [published online ahead of print". The New England Journal of Medicine (2020): 10.

27. Baron SA., et al. "Teicoplanin: an alternative drug for the treatment of coronavirus COVID-19? [published online ahead of print". The International Journal of Antimicrobial Agents (2020): 105944.

28. Liu F., et al. "Patients of COVID-19 may benefit from sustained lopinavir-combined regimen and the increase of eosinophil may predict the outcome of COVID-19 progression [published online ahead of print". International Journal of Infectious Diseases (2020): 30132-30136.

29. Cortegiani A., et al. "A systematic review on the efficacy and safety of chloroquine for the treatment of COVID-19". The Journal of Critical Care 20.20 (2020): 30390-30397.

30. Deng L., et al. "Arbidol combined with $\mathrm{LPV} / \mathrm{r}$ versus $\mathrm{LPV} / \mathrm{r}$ alone against Corona Virus Disease 2019: a retrospective cohort study [published online ahead of print". Journal of Infection 20 (2020): 30113-30114.

31. Devaux CA., et al. "New insights on the antiviral effects of chloroquine against coronavirus: what to expect for COVID-19?" The International Journal of Antimicrobial Agents (2020): 105938.

32. Sun ML., et al. "Inhibitors of RAS Might Be a Good Choice for the Therapy of COVID-19 Pneumonia". Zhonghua Jie He He Hu Xi Za Zhi 43.3 (2020): 219-222.

33. Multicenter collaboration group of Department of Science and Technology of Guangdong Province and Health Commission of Guangdong Province for chloroquine in the treatment of novel coronavirus pneumonia. "Expert consensus on chloroquine phosphate for the treatment of novel coronavirus pneumonia". Zhonghua Jie He He Hu Xi Za Zhi 43.3 (2020): 185-188. 
34. Du B., et al. "Pharmacotherapeutics for the new coronavirus pneumonia". Zhonghua Jie He He Hu Xi Za Zhi 43.3 (2020): 173-176

35. Li H., et al. "Potential antiviral therapeutics for 2019 Novel Coronavirus". Zhonghua Jie He He Hu Xi Za Zhi 43.3 (2020): 170-172.

36. Chen Q., et al. "A report of clinical diagnosis and treatment of nine cases of coronavirus disease 2019". Journal of Medical Virology (2020).

37. Chenoweth AM., et al. "Harnessing the immune system via Fc $\gamma \mathrm{R}$ function in immune therapy: A pathway to next-gen mAbs". Immunology and Cell Biology (2020).

38. Yao X., et al. "In Vitro Antiviral Activity and Projection of Optimized Dosing Design of Hydroxychloroquine for the Treatment of Severe Acute Respiratory Syndrome Coronavirus 2 (SARS-CoV-2)". Clinical Infectious Diseases (2020): 237.

39. Zhou D., et al. "COVID-19: a recommendation to examine the effect of hydroxychloroquine in preventing infection and progression". Journal of Antimicrobial Chemotherapy (2020): 114.

40. Chen YW., et al. "Prediction of the SARS-CoV-2 (2019-nCoV) 3C-like protease (3CL pro) structure: virtual screening reveals velpatasvir, ledipasvir, and other drug repurposing candidates". F1000Research 9 (2020): 129.

41. Zhu L., et al. "Successful recovery of COVID-19 pneumonia in a renal transplant recipient with long-term immunosuppression". American Journal of Transplantation (2020).

42. Batlle D., et al. "Soluble angiotensin-converting enzyme 2: a potential approach for coronavirus infection therapy?" Clinical Science 134.5 (2020): 543-545.

43. Fan HH., et al. "Repurposing of clinically approved drugs for treatment of coronavirus disease 2019 in a 2019-novel coronavirus (2019-nCoV) related coronavirus model Chin". Medical Journal (2020): 10.1097.

44. Ren JL., et al. "Traditional Chinese medicine for COVID-19 treatment”. Pharmacological Research 155 (2020): 104743.

45. Hoffmann M., et al. "SARS-CoV-2 Cell Entry Depends on ACE2 and TMPRSS2 and Is Blocked by a Clinically Proven Protease Inhibitor". Cell 8674 (2020): 30229-30224.

46. Zhou W., et al. "Potential benefits of precise corticosteroids therapy for severe 2019-nCoV pneumonia”. Signal Transduction and Targeted Therapy 5 (2020): 18.

47. Gurwitz D. "Angiotensin receptor blockers as tentative SARSCoV-2 therapeutics". Drug Development and Research (2020).
48. Fu Y., et al. "Understanding SARS-CoV-2-Mediated Inflammatory Responses: From Mechanisms to Potential Therapeutic Tools". Virologica Sinica (2020).

49. Xu J., et al. "Broad Spectrum Antiviral Agent Niclosamide and Its Therapeutic Potential". ACS Infectious Diseases (2020).

50. Chen L., et al. "Convalescent plasma as a potential therapy for COVID-19". The Lancet Infectious Diseases 20 (2020): 3014130149.

51. Richardson P., et al. "Baricitinib as potential treatment for 2019-nCoV acute respiratory disease". Lancet 395.10223 (2020): e30-e31.

52. Dong L., et al. "Discovering drugs to treat coronavirus disease 2019 (COVID-19)". Drug Discoveries and Therapeutics 14.1 (2020): 58-60.

53. Information for Clinicians on Therapeutic Options for COVID-19 Patients.

54. Gilead launches remdesivir's Phase III trials in Covid-19 patients.

55. Q Cai., et al. "Experimental Treatment with Favipiravir for COVID-19: An Open-Label Control Study". Engineering (2020).

56. Zhang J., et al. "Teicoplanin potently blocks the cell entry of 2019-nCoV". Bio Rxiv (2020).

\section{Assets from publication with us}

- Prompt Acknowledgement after receiving the article

- Thorough Double blinded peer review

- Rapid Publication

- Issue of Publication Certificate

- High visibility of your Published work

Website: https://www.actascientific.com/

Submit Article: https://www.actascientific.com/submission.php Email us: editor@actascientific.com

Contact us: +919182824667 